\title{
Numerical Simulation of Dynamic Response Characteristics of Cutting Coal and Rock by a Roller Coal Cutter
}

\author{
Kesong Fan $\mathbb{D}^{1},{ }^{1,2,3}$ Yutong Feng, ${ }^{1,2,3}$ Ruoyang Kong, ${ }^{4}$ Hua Wei, ${ }^{1,2,3}$ Wenlong Jiao, ${ }^{1,2,3}$ \\ Chenghao Fu, ${ }^{1,2,3}$ and Yunsen Zhou ${ }^{5}$ \\ ${ }^{1}$ College of Electronic and Electrical Engineering, Henan Normal University, Xinxiang 453007, Henan, China \\ ${ }^{2}$ Henan Key Laboratory of Optoelectronic Sensing Integrated Application, Xinxiang 453007, Henan, China \\ ${ }^{3}$ Academician Workstation of Electromagnetic Wave Engineering of Henan Province, Xinxiang 453007, Henan, China \\ ${ }^{4}$ College of international Education, Henan Normal University, Xinxiang 453007, Henan, China \\ ${ }^{5}$ Henan Institute of Metrology, Zhengzhou 450000, Henan, China \\ Correspondence should be addressed to Kesong Fan; 2019076@htu.edu.cn
}

Received 6 August 2021; Accepted 6 October 2021; Published 21 October 2021

Academic Editor: Marco Cocconcelli

Copyright ( $\odot 2021$ Kesong Fan et al. This is an open access article distributed under the Creative Commons Attribution License, which permits unrestricted use, distribution, and reproduction in any medium, provided the original work is properly cited.

\begin{abstract}
Currently, the identification technology of rock-coal medium is not reliable and practical, so we cannot judge the cutting state of coal-winning machine in real time. Different dynamic responses over different medium types of rock-coal can indirectly reflect the physical and mechanical parameters of rock-coal. In this study, we establish the 3-D numerical model of cutting the rock and coal by the finite element numerical simulation software in which we obtain the whole process of numerical simulation of the roller cutting coal, mudstone, and sandstone, where different dynamic responses counterpart different types of rock and coal by means of numerical experiments. The results show that when the drum keeps the average speed of cutting coal and medium forward, the instantaneous speed which is close to the average speed will have a small jump. The average speed and the torque in the cutting process can be considered as good indices to evaluate the rock and coal types. The torque from high to low is as follows: sandstone, mudstone, and coal. The average speed from high to low is as follows: coal, mudstone, and sandstone. If the portion of rock is more, the torque is higher and the average speed is lower during cutting the roof foot. This research is helpful for identifying rockcoal medium types by using related instrument to record the dynamic responses of rock-coal medium types.
\end{abstract}

\section{Introduction}

Automatic identification technology of coal and rock properties of the working face is not only the basis of automatic control of coal-winning machine but also the need for intelligent and unmanned mining. Due to the effect of large coal dust, poor visibility, complex environment, and other shortcomings [1-5], it is difficult to accurately judge the coal and rock properties in front of the drum of the coalwinning machine by direct visual observation, cutting noise, and other information. If one can distinguish the cutting medium in front of the shearer in real time, then one can automatically control the coal machine, reducing (or eliminating) the damage to the cutting teeth or avoiding gas explosion accident caused by friction spark. At the same time, treatment measures, such as preloosening fracturing, can be done for the hard rock if encountered at an earlier time [6-11]. In Chinese Energy Science and Technology Development Plan of the twelfth five-year plan, it is also clearly pointed out that the unmanned mining technology of fully mechanized coal face is an important development direction, and the focus is on the automatic identification technology of coal and rock properties to realize unmanned and automatic mining of the working face.

According to the existing literature, there are no less than 20 research methods for coal and rock identification, for example, the gamma-ray methods, which contain radioactive elements in coal rocks, the image recognition based on color and grain difference of coal and rock surface, the current and voltage threshold judgment method of cutting 
motor, the mechanical vibration analysis based on signal strength and spectral difference, the memory cutting, the infrared reflection, and so on [12-23]. Although these methods have achieved certain scientific research results, some methods have also been applied to production practices and most of the technologies have low reliability, low practicability, and hysteresis. For example, it cannot judge the cutting state of the coal mining machine in real time when the working face encounters sudden changes, such as working fault. Therefore, it is necessary to make further exploration on the basis of the existing automatic identification technology of coal and rock.

The relevant theory [24-26] of cut rocks point out that if coal and rock medium changes, the dynamic response generated by certain dynamic excitation will also change. Also, its dynamic characteristics can reflect features of physical and mechanical parameters, such as density and strength of coal and rock. Therefore, by means of numerical simulation, this study investigated the dynamic response characteristics of the coal cutter roller when cutting coal and rock and analyzed the variation rules of the characteristics, such as displacement, speed, and reverse torsion of the roller when cutting coal and rock. We can identify the cutting state of the roller in real time by the characteristic information of the cutting medium. At the same time, if the property of the medium in front of the working face is known, the dynamic characteristics can be predicted in advance. This will have very important theoretical significance and engineering value.

\section{Failure Mechanism and Failure Criteria of Coal and Rock}

\subsection{Breaking Mechanism of Coal and Rock by Truncated Tooth.} The process of cutting coal and rock is described in detail as follows. When the truncated tooth just touches the coal body, stress concentration phenomenon occurs. When stress increases to certain degree, the local coal which is in contact will be crushed into powder. After further compression, the pulverized coal will be in the intact coal body in front of the truncated tooth, forming a compact core structure, which is shown in Figure 1.

When the truncated tooth moves forward, the stress inside the dense nuclear will increase, causing the breakage of I in Figure 1 and presenting notch on the surface of coal body. Then the powder is ejected from the dense core structure. When the truncated tooth moves forward over the small caved block I, it recontacts the coal and forms a dense core structure. Meanwhile, the volume and pressure increase, leading to small parts of II to break up again. As the cycle goes on, the rate of caved coal increases and finally falls into large chunks III along the crack AB. The mechanism of breaking coal by the truncated tooth is summarized as follows. At first, the truncated tooth produces a crushing effect to the partial coal body under compressive stress. Under the shear stress effect, the coal rock body produces cracks. After the cracks are fully expanded and developed, brittle fracture occurs in the coal rock [27-30].

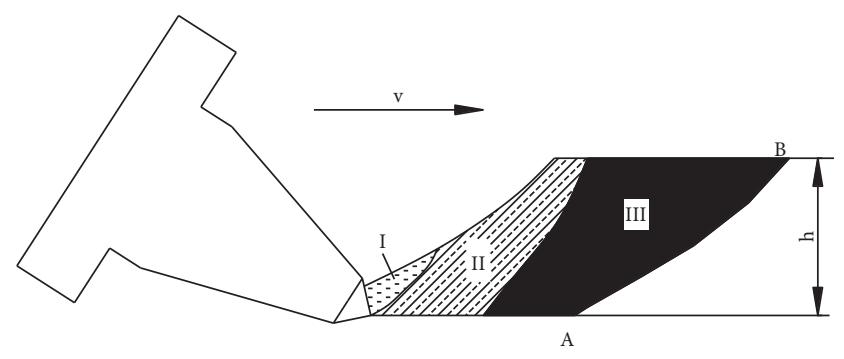

FIGURE 1: The model of the dense nuclear structure.

2.2. Coal and Rock Failure Criteria. The failure criterion of the rock represents the relationship between stress and rock strength in the state of ultimate stress. Shear failure is the main form of breaking coal and rock, and the frictional strength is equal to the bonding force against shear friction and the friction produced by the normal force on the shear surface. Although the Mohr-Coulomb failure criterion can reflect the essence of rock material failure by compression and shear, it ignores the influence of the intermediate main stress $\sigma 2$. The Dracker-Prager failure criterion makes up for this defect and can simulate the equivalent softening and hardening of rock materials as well as the inelastic bulk deformation. Therefore, this study adopts D-P failure criterion.

The cutting failure of coal and rock samples is not a transient process, but a dynamic continuous process. Therefore, failure criteria include initial failure criteria and progressive failure criteria [31].

(1) Initial failure criteria for coal and rock: the shear failure criterion predicts the initial failure state according to the shear behavior. It is assumed that the equivalent plastic strain of the rock in the initial failure state is ${\overline{\varepsilon_{s}}}^{p l}$, and ${\overline{\varepsilon_{s}}}^{p l}\left(\theta_{s}, \overline{\bar{\varepsilon}}^{p l}\right)$ is a function related to the shear stress rate $\theta_{s}$ and the plastic strain rate $\dot{\bar{\varepsilon}}^{\cdot p l}$. When the following criterion is met, the rock begins to break down:

$$
\omega_{s}=\int \frac{d \bar{\varepsilon}^{p l}}{{\overline{\varepsilon_{s}}}^{p l}\left(\theta_{s}, \dot{\varepsilon^{p l}}\right)}=1 .
$$

Among them, $\omega_{s}$ is a state variable. When the plastic deformation increases with the proportion of equivalent plasticity, $\omega_{s}$ increases at the same time. For each incremental step in the analysis, the increment $\mathrm{V} \omega_{s}$ of $\omega_{s}$ is calculated according to the following equation:

$$
\triangle \omega_{s}=\frac{\triangle \bar{\varepsilon}^{p l}}{{\overline{\varepsilon_{s}}}^{p l}\left(\theta_{s}, \dot{\bar{\varepsilon}}^{p l}\right)} \geq 0 .
$$

(2) Criterion for progressive failure of coal and rock: during the process of coal and rock being cut and broken, the strength of coal and rock decreases continuously at first and finally leads to the breaking 
of coal and rock (as shown in Figure 2). The solid line represents the failure stress-strain curve, and the dotted line represents the corresponding nonfailure stress-strain curve.

When the rock element is subjected to a stress greater than its yield stress $\sigma_{0}$, the rock element begins to move from the elastic phase to the plastic hardening phase, but it is not destroyed at this time. Under the continuous action of the truncated tooth, when the stress value of the rock is greater than the critical yield stress $\sigma_{y 0}$ and the corresponding critical plastic strain ${\overline{\varepsilon_{0}}}^{p l}$, the rock enters the stage of strain softening and the damage factor $D$ increases continuously. When the equivalent plastic strain value reaches $\overline{\varepsilon_{f}} p l$, the damage factor $D=1$, the rock element completely fails, and spalling from the rock mass forms a groove.

\section{Numerical Model of Roller Cutting}

3.1. Basic Assumptions. It is a complicated process to cut the coal wall of the working face with the coal cutter roller's truncated tooth, which is affected by the mechanical parameters of coal and rock, the power and model number of the coal cutter, and the stress state of coal and rock. In order to facilitate the numerical calculation, the following basic assumptions are made:

(1) Because the process of coal cutter cutting coal and rock is completed through the roller's truncated tooth, in order to reduce the amount of calculation without affecting the calculation results, we can ignore the motor, rocker, base, and other components of the coal cutter, only to establish the coal cutter roller model.

(2) Because the coal cutter roller has a high strength and hardness compared with the coal rock mass, the model can be assumed as a rigid body.

(3) The cutting of coal and rock by the roller is carried out parallel to the direction of the working face. The track of the roller cuts coal, and the rock is well controlled. It moves forward along a straight line and the roller rotates around the axis.

(4) After the coal and rock units are cut and broken, the problem of repeated destruction is no longer considered, and the broken coal and rock units no longer affect the subsequent cutting process.

(5) The primary cutting depth of the coal wall cut by the drum was fixed at $0.8 \mathrm{~m}$. The dynamic conditions on the roller are traction force $f=200 \mathrm{kN}$, rotation speed $r=4.18 \mathrm{rad} / \mathrm{s}$ remained unchanged, and the upper and lower boundary of the coal wall was completely fixed.

3.2. Building the Cutting Model. Through a lot of investigations on the common rocks in the coal face, it is found that there are mainly mudstone, sandstone, sandy mudstone, and other materials. Coal sample, mudstone, and sandstone are taken from Luszigou Coal Mine in Zhongneng, Shanxi Province, China. The standard specimens were made (as shown

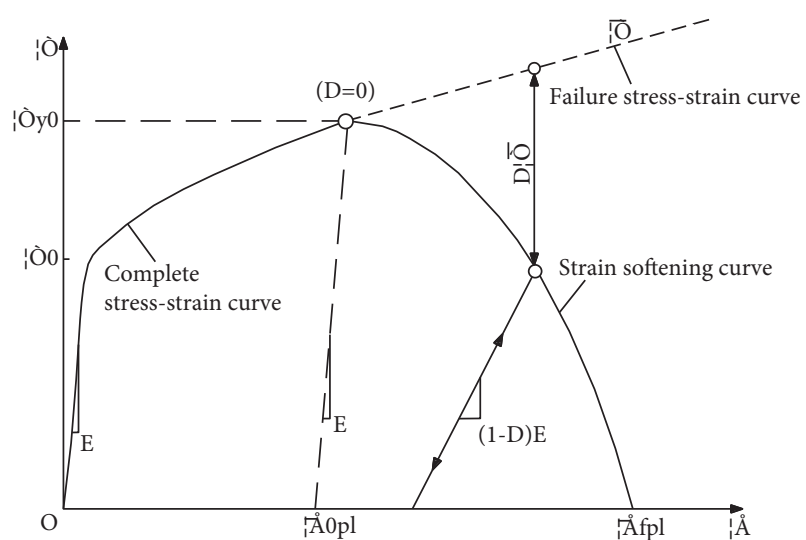

FIGURE 2: Stress-strain curve during failure progress of rock.

in Figure 3). Relevant mechanical parameters were tested in the State Key Laboratory of Efficient Mining and Clean Utilization of Coal Resources. The results are shown in Table 1.

The coal cutter roller and the coal wall model of the working face established by CAE software are shown in Figure 4 . The left side is a coal cutter roller model with a diameter of $2 \mathrm{~m}$ and a width of $0.8 \mathrm{~m}$. The right side is a coal rock model of the working face with a length of $10 \mathrm{~m}$, width of $2 \mathrm{~m}$, and height of $4 \mathrm{~m}$.

The coal rock model and the roller model are divided by a tetrahedral free grid. In order to ensure the calculation accuracy and save the calculation time, the grid was refined in the areas that had a great influence on the roller cutting of coal and rock, whereas the grid size was appropriately increased in other areas [32].

\section{Analysis of Simulation Results}

4.1. The Failure Process of Coal Rock Cut by Roller. The central position of the roller at point $o$ is selected and a constant forward traction of $200 \mathrm{kN}$ and a rotation speed of $4.18 \mathrm{rad} / \mathrm{s}$ are applied. The traction provides forward power for the roller to cut coal and rock by the truncated tooth. The rotation speed provides the original rotation speed for the roller, which is driven to the coal and rock interface under dynamic conditions. The truncated tooth is in contact with the interface of the coal and rock wall at first, and then, friction is generated between the truncated tooth and the coal and rock. The rotation of the truncated tooth starts to cut the coal and rock. Then, the coal and rock will be subject to friction, pressure, and cutting force of the truncated tooth. When the force of coal and rock is greater than its yield strength, it will produce yield change and enter the stage of plastic hardening.

When the truncated tooth continuously acts on the coal and rock mass, the stress is greater than the failure strength of the coal and rock, which will be destroyed and cut off by the truncated tooth. This process is simulated by setting up units in CAE software. The above process reciprocates and causes the coal and rock wall of the working face to be continuously cut. Figure 5 shows the cutting displacement and plastic zone distribution of the roller at different time periods in the process of cutting the coal seam. 


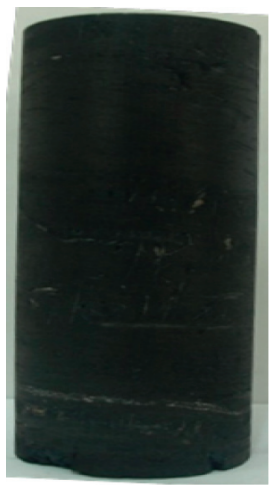

(a)

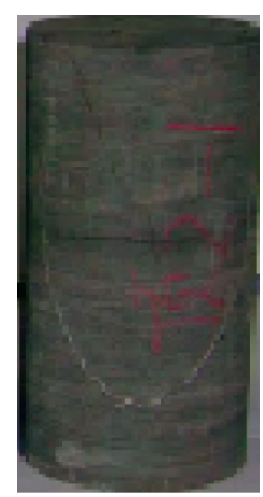

(b)

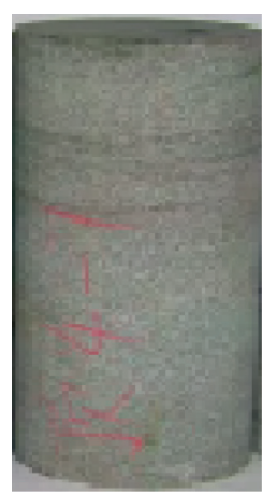

(c)

Figure 3: Coal and rock samples of working face. (a) Coal. (b) Mudstone. (c) Sandstone.

TABLE 1: Physical and mechanical parameters of coal and rock.

\begin{tabular}{lccccc}
\hline Rock types & $\begin{array}{c}\text { Density } \\
\rho\left(\mathrm{kg} \cdot \mathrm{m}^{-3}\right)\end{array}$ & $\begin{array}{c}\text { Elasticity modulus } \\
E(\mathrm{GPa})\end{array}$ & $\begin{array}{c}\text { Poisson's ratio } v \\
\text { Uniaxial compressive strength (MPa) }\end{array}$ & Strength of extension (MPa) \\
\hline Coal & 1574 & 4.29 & 0.35 & 13.5 & 0.73 \\
Mudstone & 2612 & 12 & 0.25 & 37.7 & 3.07 \\
Sandstone & 2751 & 30 & 0.26 & 89.1 & 10.61 \\
\hline
\end{tabular}

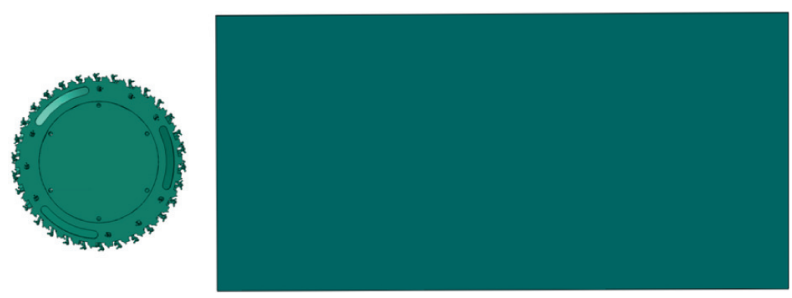

Figure 4: Working face model of a coal cutter roller.

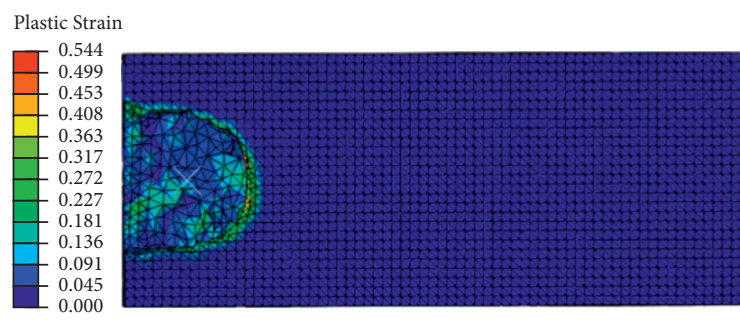

(a)

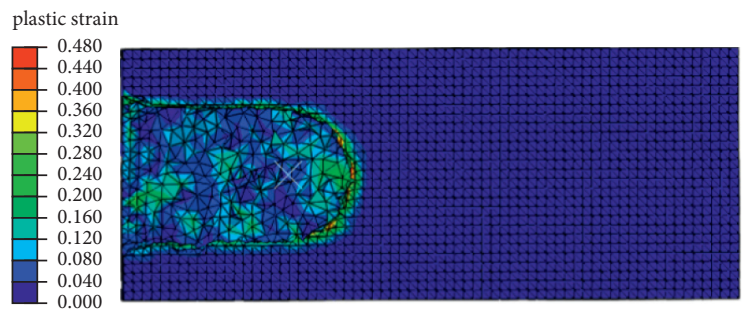

(c)

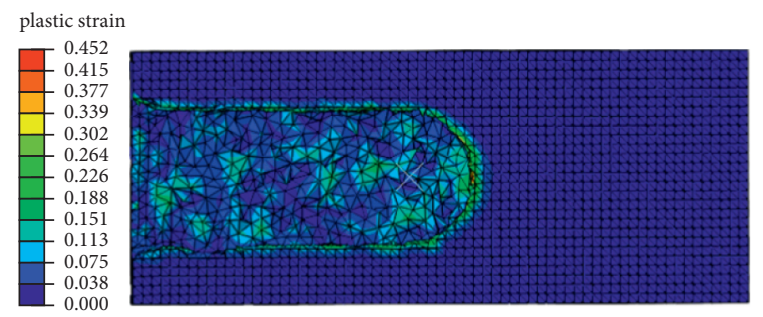

(b)

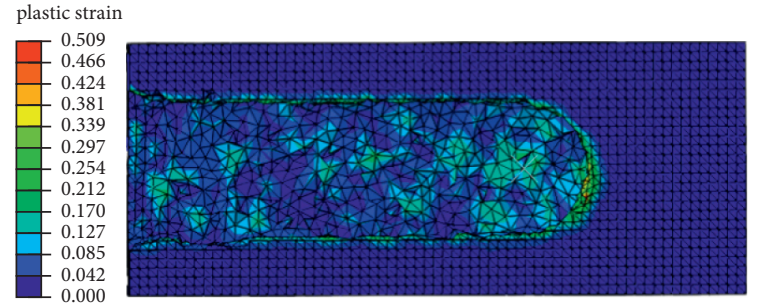

(d)

Figure 5: The plastic zone distribution of roller cutting coal. (a) $T=30$ seconds. (b) $T=60$ seconds. (c) $T=90$ seconds. (d) $T=120$ seconds. 
As can be seen from Figure 5, the position of the roller at different time periods goes from shallow to deep. When $t=30 \mathrm{~s}$, the roller was cut to the position of $2.3 \mathrm{~m}$. When $t=60 \mathrm{~s}$, it was cut to the position of $3.97 \mathrm{~m}$. When $t=90 \mathrm{~s}$, the position was cut to $5.8 \mathrm{~m}$. When $t=120 \mathrm{~s}$, it was cut to $7.71 \mathrm{~m}$ position. According to the cutting position of the roller at different time periods, the average cutting speed can be calculated. The average cutting speed of $2.9 \sim 30 \mathrm{~s}$ is $0.07 \mathrm{~m} / \mathrm{s}$, $30 \sim 60 \mathrm{~s}$ is $0.058 \mathrm{~m} / \mathrm{s}, 60 \sim 90 \mathrm{~s}$ is $0.061 \mathrm{~m} / \mathrm{s}$, and $90 \sim 120 \mathrm{~s}$ is $0.064 \mathrm{~m} / \mathrm{s}$. That is to say, the average cutting speed is between 0.058 and $0.07 \mathrm{~m} / \mathrm{s}$, and the roller does not completely cut coal in the first 30 seconds, so the average cutting speed will be higher. It can be seen that the average cutting speed presents a slight fluctuation trend, with a small range of variation. It can be speculated that if the coal cutter roller cuts the coal and rock medium of the same nature, it will cut forward with an average speed.

4.2. Dynamic Characteristics of Cutting a Single Medium. If dynamic conditions, such as traction $f$, rotation speed $r$, and boundary conditions, remain unchanged, dynamic response characteristics of coal seam, mudstone, and sandstone are obtained by numerical simulation.

\subsubsection{Analysis of Inverse Moment Response When Cutting a}

Single Medium. As we know, if the roller rotates to cut coal and rock medium, it is necessary to overcome resistance of the medium to roller's truncated tooth. Then, the roller generates an inverse torque to the truncated tooth. The reaction torque curves of three media obtained by simulation are shown in Figure 6.

According to Figure 6, there are two inflection points A and $\mathrm{B}$ in the curve between inverse torque and time relationship. Before point $A$, the inverse torque is 0 . The inverse torque between points A and B fluctuates slightly. After point $B$, the inverse torque decreases to 0 again. According to this feature, it can be concluded that the roller does not contact with the coal and rock medium before point A. Between points $\mathrm{A}$ and $\mathrm{B}$, it is the cutting process of the roller. Finally, the cutting process is over after point B. The reverse moment of cutting the same medium shows a phenomenon of big and small. The reason is that the process of breaking the coal rock medium needs to go through three stages of elastic deformation, plastic deformation, and crushing. The resistance of the medium to the roller's truncated tooth in each stage is inconsistent. The rock element suffers the least resistance in the elastic stage. At the same time, resistance in the plastic stage increases gradually, and the resistance is greatest before failure occurs at the ultimate stress state. After the failure of the element, the new element is cut and this process will be repeated and continued.

But when cutting a different medium, the change of resistance to the roller is not consistent. The inverse torque of coal is mostly concentrated in the range of $0 \sim 600 \mathrm{kN} \cdot \mathrm{m}$, mudstone torque is in the range of $0 \sim 1200 \mathrm{kN} \cdot \mathrm{m}$, and sandstone torque is in the range of $0 \sim 1685 \mathrm{kN} \cdot \mathrm{m}$. The average inverse torque relationship can be obtained by taking the inverse torque linear trend line of three media. The relationship is "sandstone $>$ mudstone $>$ coal seam." The change reason of the inverse torque is that the strength and hardness of medium are inconsistent. That is to say, the strength of the coal is small and the strength of the sandstone is larger. The above coal and rock failure criterion theory points out that only when the stress subjected to the medium reaches its critical yield stress, the failure of the rock unit occurs. Therefore, the failure of coal needs to overcome the smaller working resistance, whereas the failure of sandstone needs to overcome larger working resistance.

\subsubsection{Displacement Response Analysis When Cutting a Single} Medium. Cutting displacement refers to the depth of the center point of the drum into the medium when cutting the medium. The simulated cutting displacements and time curves of coal, mudstone, and sandstone are shown in Figure 7.

The relation curve between cutting displacement and time in is shown in Figure 7. Point A (the roller is not in contact with coal and rock medium) indicates that roller is in a state of free rotation. Then, displacement parameters increase significantly. The displacement and time images between A and B (when the roller is cutting the medium) show an approximate linear "step up" growth, but the displacement and time slopes are lower than in the stage of free rotation. The reason is that the roller cutting the medium needs to overcome the resistance and apply work.

Figure 7 shows that the displacements-time curve of the cutting medium fluctuates up and down near a straight line with a certain slope. Therefore, the average cutting speed of the medium can be figured out by the line slope. The average cutting speed of the three media is $0.064 \mathrm{~m} / \mathrm{s}, 0.031 \mathrm{~m} / \mathrm{s}$, and $0.012 \mathrm{~m} / \mathrm{s}$, respectively. That is to say, the general relationship of the average cutting speed is "coal seam > mudstone $>$ sandstone." Therefore, the average cutting speed is a good reflection of medium type.

4.2.3. Velocity Response Analysis When Cutting a Single Medium. The curve of instantaneous cutting speed and time among the three media obtained by simulation is shown in Figure 8.

Figure 8 shows that the instantaneous velocity rose rapidly before point $\mathrm{A}$ (the roller did not contact with the medium). It fluctuates greatly between $\mathrm{A}$ and $\mathrm{B}$ (during cutting) and suddenly increases in A straight line after point B (after cutting). It can be seen that no matter what kind of media the drum cuts, the cutting speed fluctuates all the time. The changing rule of the cutting speed is exactly the reflection of the resistance during the cutting process analyzed above. But when the cutting medium is different, the wave fluctuation is different, which is reflected in the velocity amplitude and the number of rebounds (that is, the number of vibrations with the velocity below $0^{\prime \prime}$ ). For example, the instantaneous velocity of coal seam cutting is between 0 and $0.11 \mathrm{~m} / \mathrm{s}$, and no rebound is found. The instantaneous velocity of mudstone cutting is between -0.1 and $0.14 \mathrm{~m} / \mathrm{s}$. There is a small amount of rebound, and a small part of the instantaneous velocity is less than 0 . The instantaneous 
Time (s)

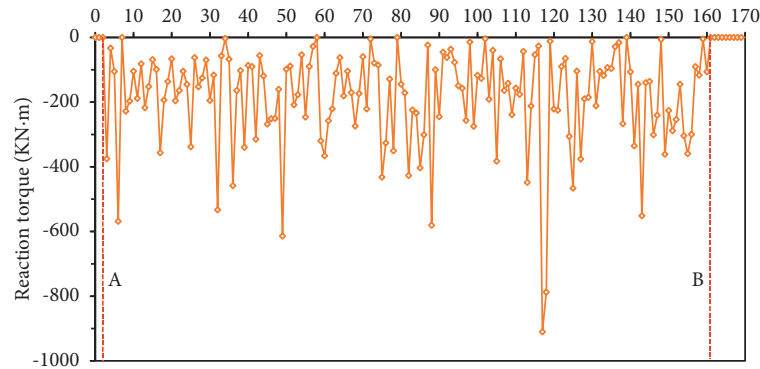

(a)
Time (s)

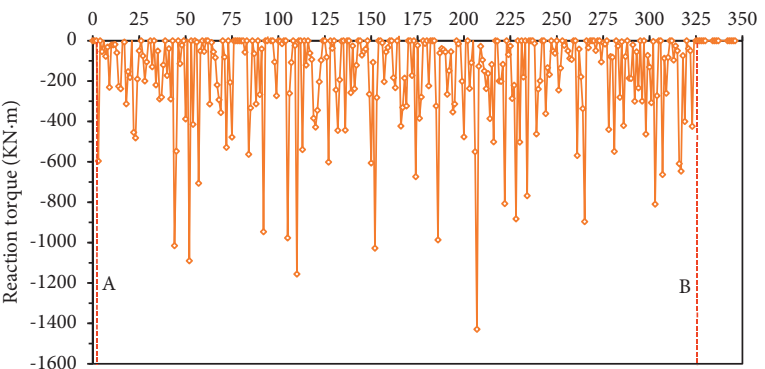

(b)

Time (s)

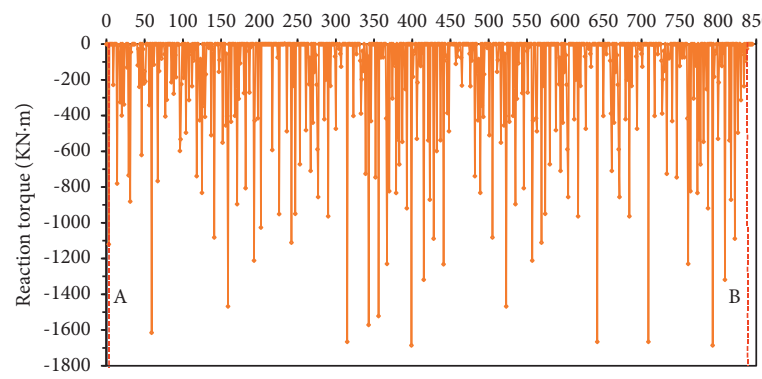

(c)

Figure 6: The relation curve between countertorque and time. (a) Coal. (b) Mudstone. (c) Sandstone.

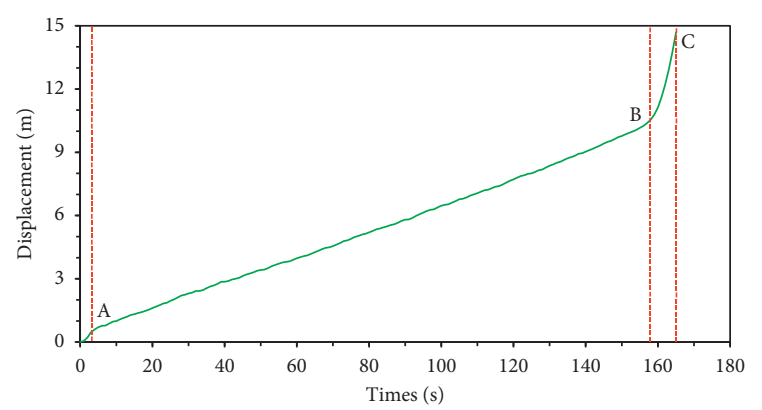

(a)

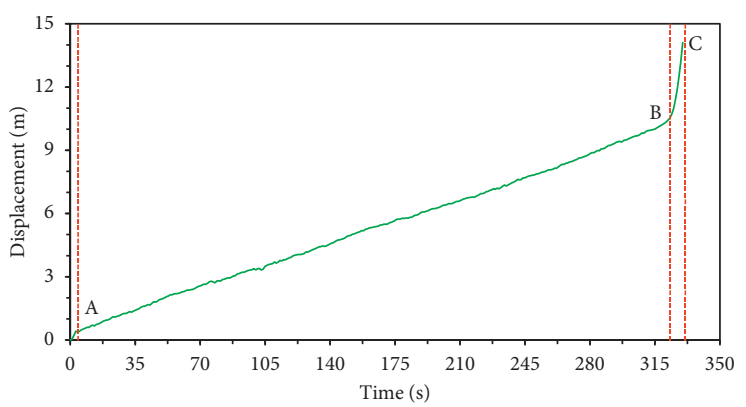

(b)

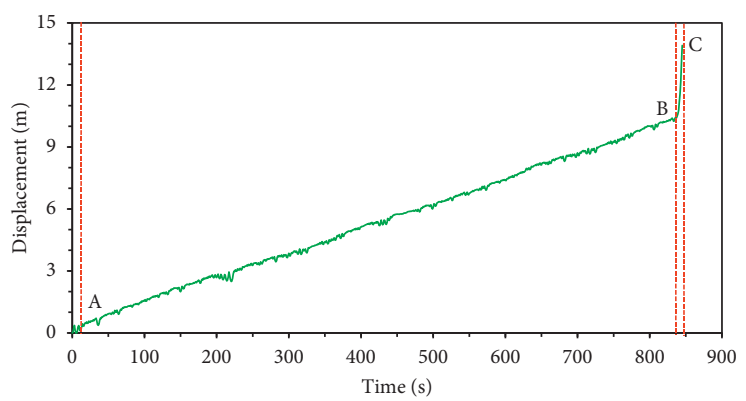

(c)

Figure 7: The relation curve between displacement and time. (a) Coal. (b) Mudstone. (c) Sandstone.

velocity of sandstone cutting is between -0.27 and $0.29 \mathrm{~m} / \mathrm{s}$, and a large number of springback are found. That is to say, half of the total instantaneous velocity is less than 0 .

The instantaneous velocity fluctuation of different media is inconsistent because the mechanical properties of coal and rock of the cutting media change. When the cutting medium varies, the roller needs to overcome different working resistance. According to the analysis of inverse moment response, it is pointed out that the largest resistance needs to be overcome when cutting the sandstone and the smallest 


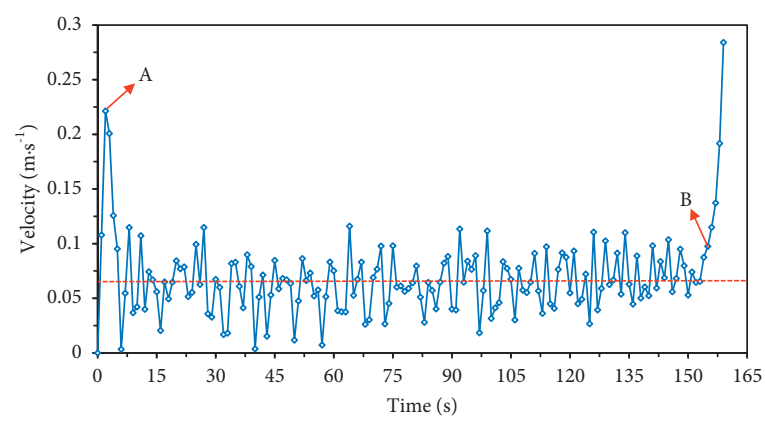

(a)

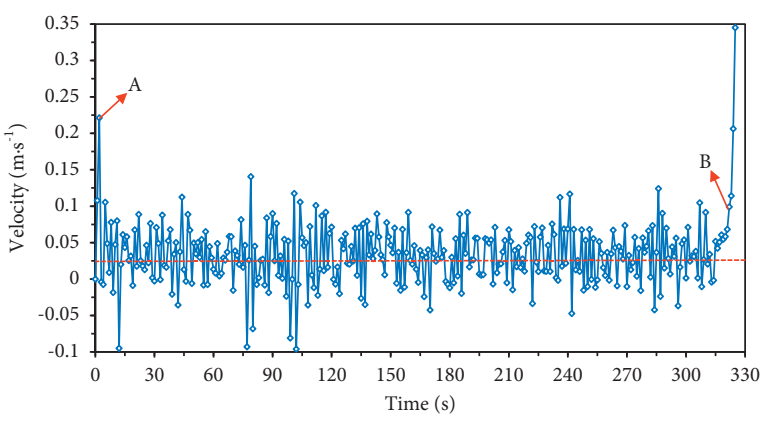

(b)

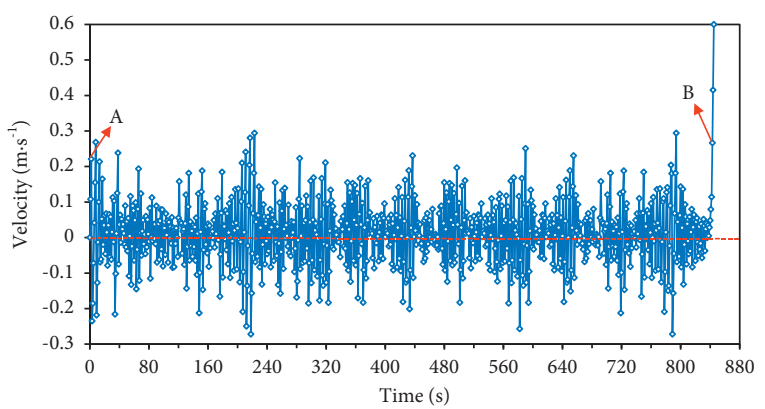

(c)

Figure 8: The relation curve between velocity and time. (a) Coal. (b) Mudstone. (c) Sandstone.

resistance needs to be overcome when cutting the coal seam. Therefore, the instantaneous velocity fluctuation is the largest when cutting the sandstone and the smallest when cutting the coal seam.

When the traction force suffered by the roller is small, it is not enough to instantly destroy the medium with greater strength. The phenomenon of "falling-forward-refallingback" will be generated, and repeated destruction of the medium will not be carried out until the rock unit is completely destroyed, which is also the reason for the springback phenomenon during cutting. Due to the high strength of the sandstone, it is not easy to be damaged. When the traction force is relatively small, a complete rock unit needs repeated cutting to be destroyed, so the number of springback is more. However, the strength of mudstone and coal seam is small and relatively easy for destruction, so there are fewer times of rebound. Or only the speed decreases, and no rebound phenomenon occurs. Therefore, if the strength and hardness of the coal rock affect the cutting speed of the roller, different instantaneous cutting speeds can precisely reflect the type of cutting medium and springback during cutting is also a reflection of mechanical parameters of the medium rock.

4.3. Dynamic Characteristics of Cutting the Coal-Rock Combination Model. Due to fluctuation variation of the coal seam, the roller often cuts some gangue when the coal cutter roller cuts the coal seam in the working face, so the phenomenon of "cutting the top" appears. Therefore, the dynamic characteristic of the roller cutting coal seam is different from gangue, which will change with the change in the thickness of "cutting the top" at the same time. The above analysis indicates that lithology of cutting the medium can be distinguished according to the dynamic characteristics of single medium. In order to explore the dynamic characteristics of the roller when the phenomenon of "cutting the top" occurs, the coal and rock medium combination model is established for numerical analysis.

4.3.1. Coal and Rock Combination Scheme Design. The CAE finite element software is used to establish the three-dimensional combination model of coal-mudstone and coalsandstone medium. The overall height of the model is $4 \mathrm{~m}$, and the coal cutter height remains unchanged $(2 \mathrm{~m})$. According to different proportions of coal and rock medium, four scheme models are designed, which are shown in Figure 9. The first scheme is that the coal seam thickness cut by the roller is $1.67 \mathrm{~m}$ and mudstone is $0.33 \mathrm{~m}$. Therefore, the proportion of mudstone is $1 / 6$. The second scheme is that coal seam is $1.33 \mathrm{~m}$ and mudstone is $0.67 \mathrm{~m}$ thick. Therefore, the proportion of mudstone is $1 / 3$. The third plan is that coal seam is $1.67 \mathrm{~m}$ thick and sandstone is $0.33 \mathrm{~m}$ thick. Therefore, the proportion of sandstone is $1 / 6$. The fourth plan is that coal seam is $1.33 \mathrm{~m}$ thick and the sandstone is $0.67 \mathrm{~m}$ thick. Therefore, the proportion of sandstone is $1 / 3$.

\subsubsection{Analysis of Inverse Moment Response When Cutting} Coal and Rock Assemblage. The dynamic characteristics of different combined models were obtained through numerical calculation. The reaction moment curves of the obtained models are shown in Figure 10.

As can be seen from Figure 10, there is a great difference in the reverse torque characteristics of the combination 


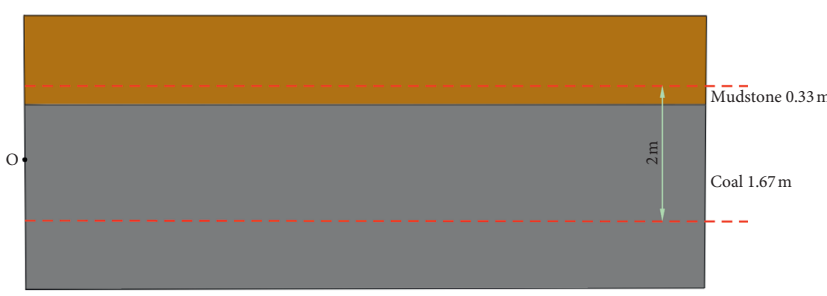

(a)

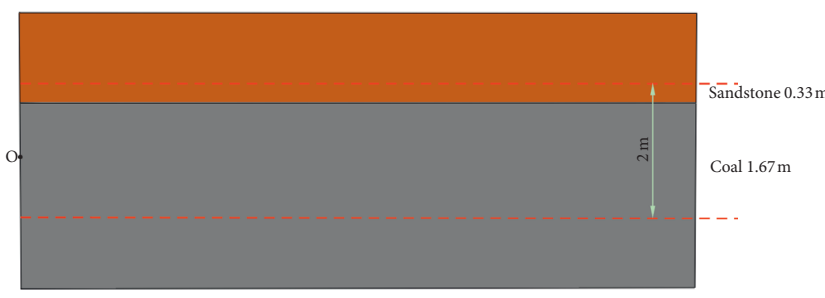

(c)

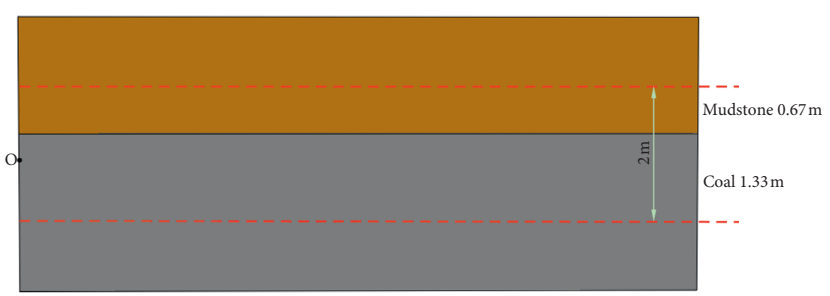

(b)

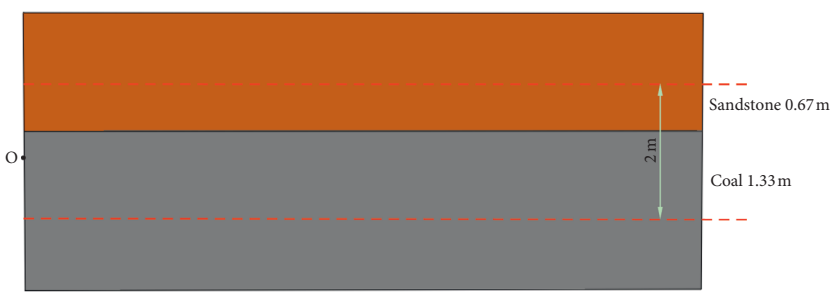

(d)

Figure 9: The combination model of coal and rock. (a) Plan (i) (b) Plan (ii). (c) Plan (iii). (d) Plan (iv).

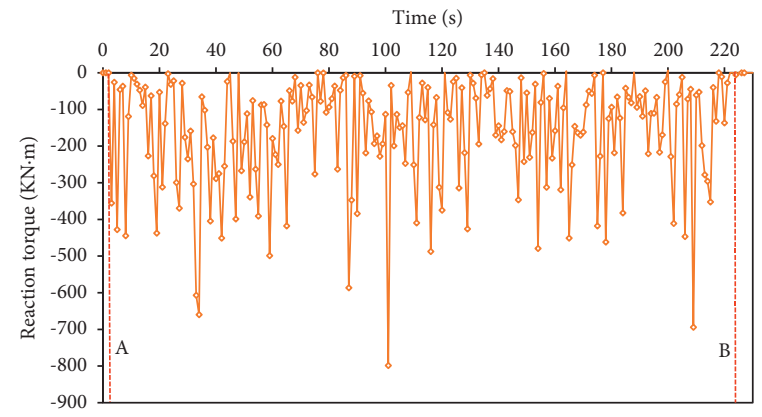

(a)

Time (s)

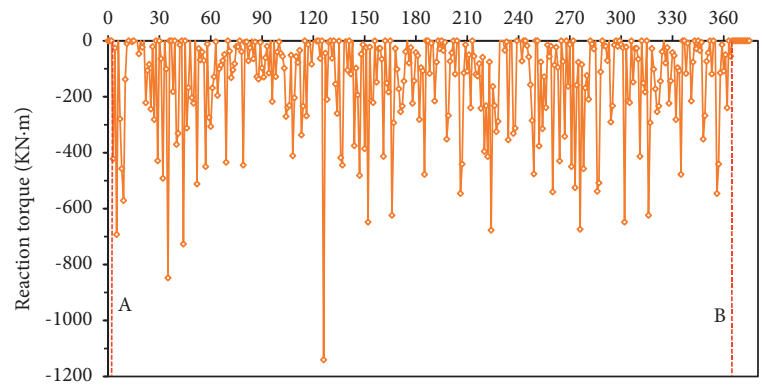

(c)

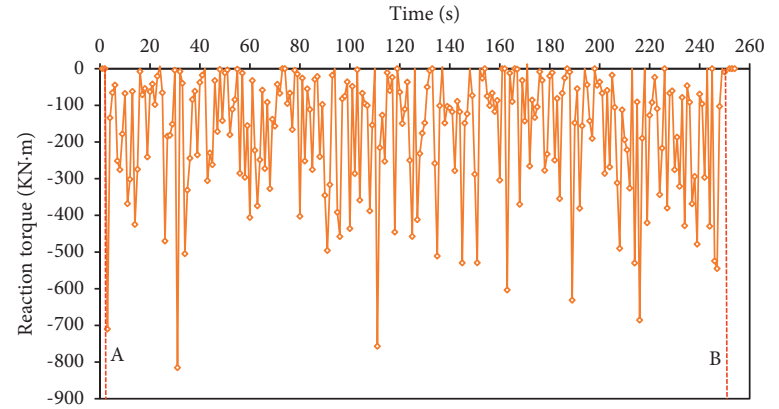

(b)

Time (s)

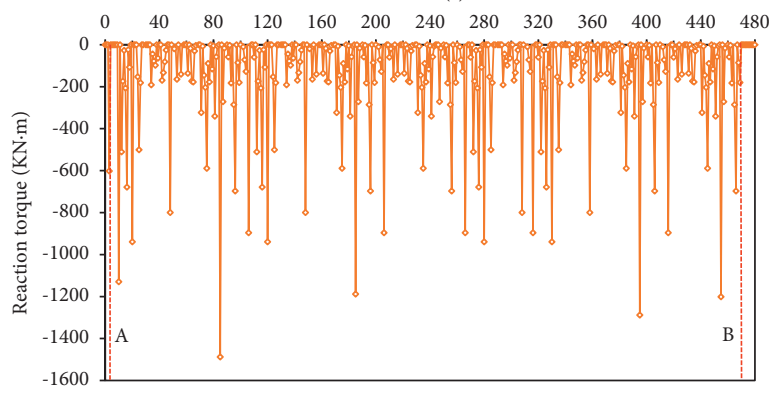

(d)

Figure 10: The relation curve between countertorque and time. (a) Plan (i) (b) Plan (ii). (c) Plan (iii). (d) Plan (iv).

model. Among them, the reverse torque of plan (i) is concentrated in the range of $0 \sim 650 \mathrm{kN} \cdot \mathrm{m}$, plan (ii) in the range of $0 \sim 700 \mathrm{kN} \cdot \mathrm{m}$, plan (iii) in the range of $0 \sim 700 \mathrm{kN} \cdot \mathrm{m}$, and plan (iv) in the range of $0 \sim 1200 \mathrm{kN} \cdot \mathrm{m}$. It can be seen that the reaction force suffered by the roller cutting the coal and rock combination model is larger than that suffered by roller cutting the single coal seam medium (Figure 6(a)). The reverse torque of plans (ii) and (iii) is larger than that of plan (i). The reverse torque of plan (iv) is larger than that of plans (ii) and (iii). By comparing the characteristics of the reverse torque, it can be concluded that the roller reverse torque is between the cutting single coal seam and rock stratum. The more parts of mudstone or sandstone are cut, the greater the reaction force will be. When the truncated mudstone and sandstone parts are equal, the truncated coal-sandstone combination model is subjected to greater reaction force than the coal-mudstone model.

The reason that reverse torque presents this characteristic is that different media have different strengths. Based on the above analysis of the coal and rock failure process, it is found that cutting the sandstone needs to overcome the largest resistance, followed by mudstone, and the smallest being coal seam. Since the resistance to be overcome in cutting the coal seam is same, the total resistance to be 


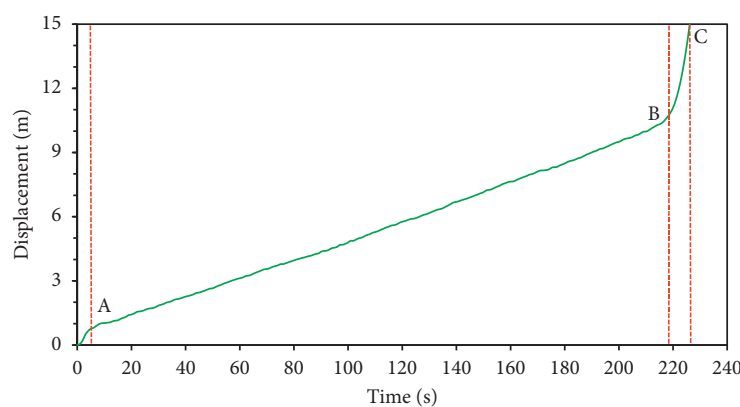

(a)

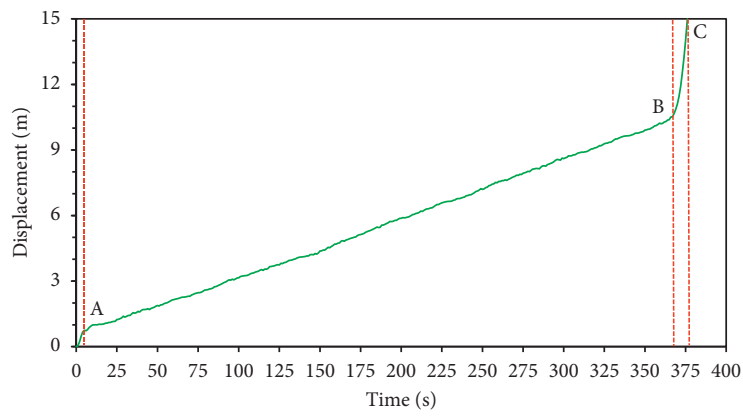

(c)

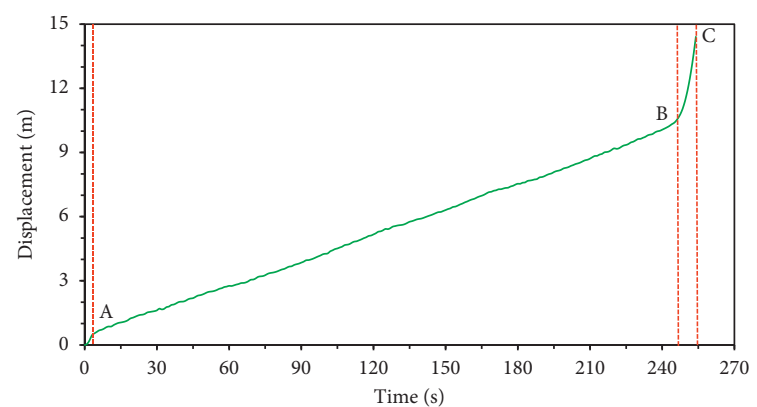

(b)

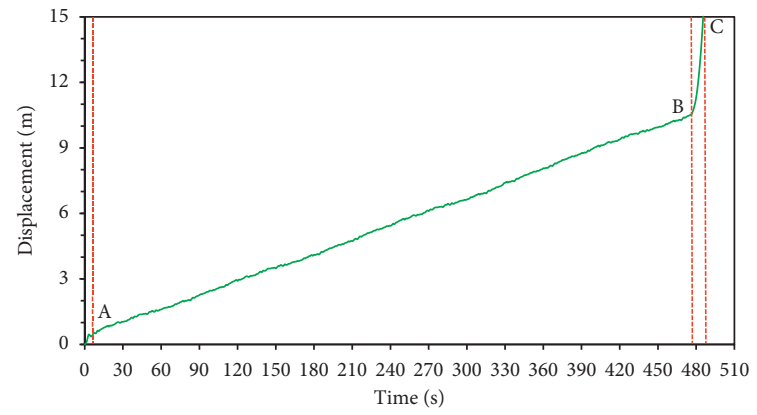

(d)

Figure 11: The relation curve between displacement and time. (a) Plan (i) (b) Plan (ii). (c) Plan (iii). (d) Plan (iv).

overcome in cutting the coal and rock combination model is determined by the strata.

\subsubsection{Analysis of Displacement Response in Cutting the Coal-} Rock Assemblage. The displacement dynamic responses of different scheme models obtained by numerical calculation are shown in Figure 11.

As can be seen from the relation curve between cutting displacement and time in Figure 11, the combination model of coal and rock cutting by the cylinder is similar to that of cutting a single medium. The relation between displacement and time is still nearly linear; that is, the roller maintains a certain average speed of forward cutting. It can be seen from the variation of the average cutting velocity that the average cutting velocity of the combined model is between the coal seam and rock strata with a single cutting medium. The greater the proportion of the cutting strata, the lower the average cutting speed. When the proportion of the truncated mudstone or sandstone is the same, the average velocity of the truncated coal-sandstone assemblage is lower than that of the truncated coal-mudstone assemblage model. The change of the average cutting velocity is the reflection of the characteristic of the cutting reverse torque.

4.3.4. Velocity Response Analysis When Cutting the CoalRock Assemblage. The instantaneous velocity responses of different scheme models obtained by numerical calculation are shown in Figure 12.

The relation curve between cutting speed and time is shown in Figure 12. Although the instantaneous cutting velocity of each model shows obvious difference, which is similar to that of cutting a single coal rock medium, it fluctuates up and down near the average cutting velocity. Compared with the single cutting of coal seam medium (Figure 8(a)), the fluctuation range of instantaneous velocity in scheme 1 is smaller because the average velocity in cutting scheme 1 model is smaller. In scheme 1 , the instantaneous velocity of some position points is less than 0 , indicating the springback phenomenon occurred because the mudstone part cannot be destroyed at the same time.

Compared with the instantaneous velocity of plan (i), the amplitude of instantaneous velocity of plan (iii) increases and the number of rebounds increases. It shows that when the cut part of the mudstone increases, the instantaneous velocity changes greatly. Then, the model can be destroyed only when more rebound phenomenon occurs. At the same time, the change in instantaneous velocity in schemes (ii) and (iv) is similar to that in schemes (i) and (iii), which indicate that when the cutting gangue part increases, it is more difficult to cut the combined medium of coal and rock by the roller, resulting in larger amplitude fluctuation of instantaneous velocity and increase in the number of springback.

4.4. Summary of Dynamic Characteristics. According to the dynamic characteristics of different coal and rock media obtained through the above numerical calculation and analysis, the summary is shown in Table 2 .

As can be seen from Table 2, when a single medium is cut by a roller coal cutter, the larger the medium strength is, or when cutting the combined medium of coal and rock, the more the coal and rock parts are cut, the greater the reaction torque on the roller will be. The lower the average cutting velocity is, the larger the instantaneous velocity fluctuation is and the more the number of rebounds is. Because the average cutting speed is the most important index of the 


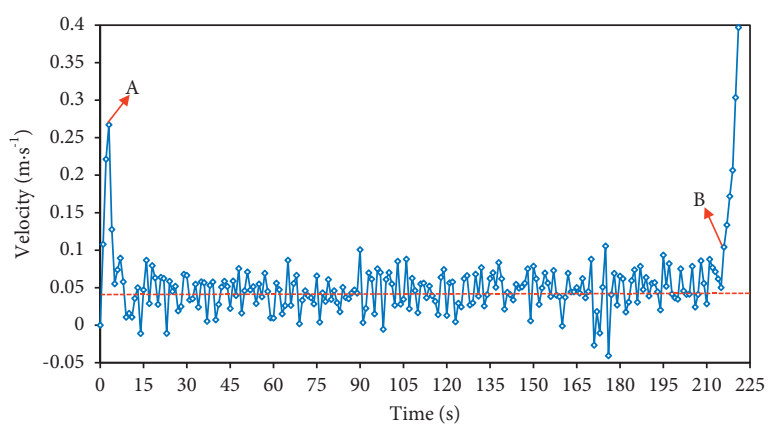

(a)

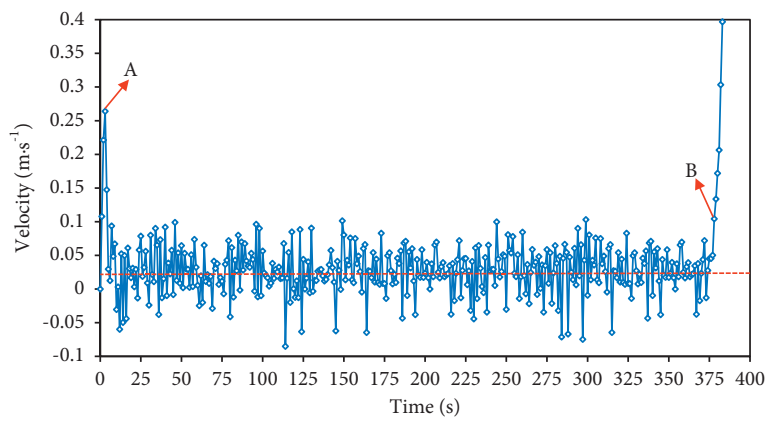

(c)

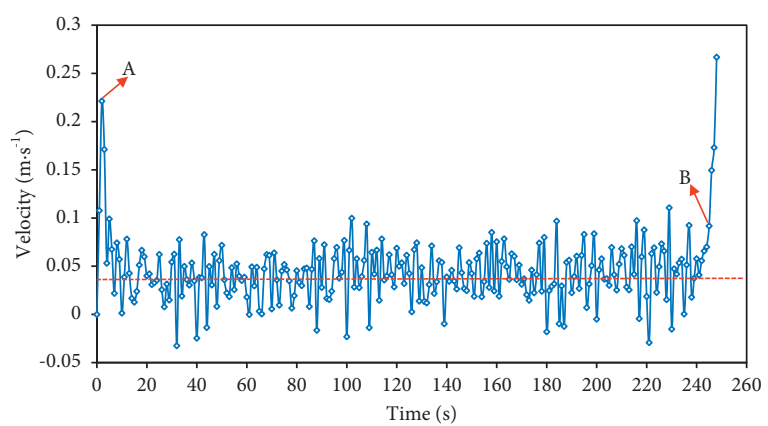

(b)

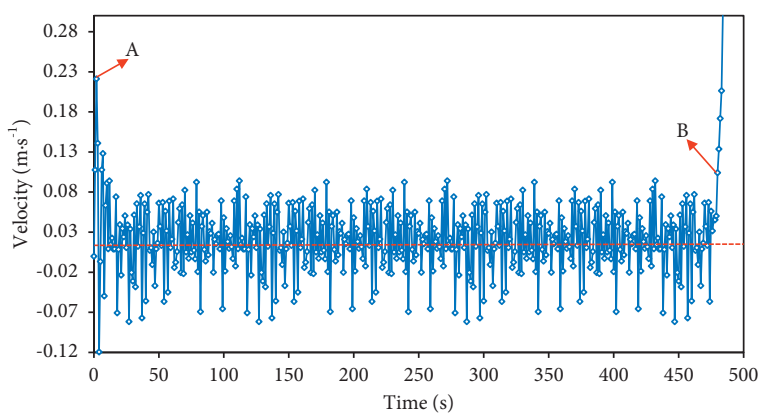

(d)

Figure 12: The relation curve between velocity and time. (a) Plan (i). (b) Plan (ii). (c) Plan (iii). (d) Plan (iv).

TABle 2: Dynamic characteristics of different media.

\begin{tabular}{|c|c|c|c|c|}
\hline \multirow[b]{2}{*}{ Cuting medium } & \multicolumn{4}{|c|}{ Dynamic behaviour } \\
\hline & $\begin{array}{l}\text { Reaction torque } \\
(\mathrm{kN} \cdot \mathrm{m})\end{array}$ & $\begin{array}{l}\text { Average cutting } \\
\text { velocity }\left(\mathrm{m} \cdot \mathrm{s}^{-1}\right)\end{array}$ & $\begin{array}{l}\text { Instantaneous velocity } \\
\left(\mathrm{m} \cdot \mathrm{s}^{-1}\right)\end{array}$ & Rebound phenomenon \\
\hline Single coal seam & $0 \sim 600$ & 0.64 & $0 \sim 0.11$ & $\begin{array}{l}\text { No rebound } \\
\text { phenomenon }\end{array}$ \\
\hline $\begin{array}{l}\text { Coal-mudstone assemblage, mudstone } \\
\text { accounting for } 1 / 6\end{array}$ & $0 \sim 650$ & 0.45 & $-0.04 \sim 0.08$ & $\begin{array}{c}\text { Rebound points account } \\
\text { for } 2 \%\end{array}$ \\
\hline $\begin{array}{l}\text { Coal-mudstone assemblage, mudstone } \\
\text { accounting for } 1 / 3\end{array}$ & $0 \sim 700$ & 0.41 & $-0.04 \sim 0.1$ & $\begin{array}{l}\text { Rebound points account } \\
\text { for } 7 \%\end{array}$ \\
\hline Single mudstone & $0 \sim 1200$ & 0.31 & $-0.1 \sim 0.14$ & $\begin{array}{l}\text { Rebound points account } \\
\text { for } 18 \%\end{array}$ \\
\hline $\begin{array}{l}\text { Coal-sandstone assemblage, sandstone } \\
\text { accounting for } 1 / 6\end{array}$ & $0 \sim 700$ & 0.28 & $-0.08 \sim 0.1$ & $\begin{array}{l}\text { Rebound points account } \\
\text { for } 20 \%\end{array}$ \\
\hline $\begin{array}{l}\text { Coal-sandstone assemblage, sandstone } \\
\text { accounting for } 1 / 3\end{array}$ & $0 \sim 1200$ & 0.21 & $-0.1 \sim 0.1$ & $\begin{array}{l}\text { Rebound points account } \\
\text { for } 36 \%\end{array}$ \\
\hline Single sandstone & $0 \sim 1685$ & 0.12 & $-0.27 \sim 0.29$ & $\begin{array}{l}\text { Rebound points account } \\
\text { for } 45 \%\end{array}$ \\
\hline
\end{tabular}

medium cut by the roller. In order to qualitatively study the change of average cutting speed with coal and rock medium, the numerical simulation method is adopted on the basis of the abovementioned way. The change of the average cutting speed of the roller coal cutter was further studied when the proportion of mudstone and sandstone was $1 / 2,2 / 3$, and $5 / 6$, as shown in Figure 13.

As can be seen from Figure 13, with the increase of the proportion of gangue cut by the roller, the average cutting speed decreases gradually and presents a nonlinear relationship. When cutting a single coal seam medium, the average velocity is $0.64 \mathrm{~m} / \mathrm{s}$. When cutting a part of gangue, which accounts for only $16.7 \%$, the average velocity drops suddenly. When the gangue is mudstone, the average velocity dropped to $0.45 \mathrm{~m} / \mathrm{s}$; when the gangue is sandstone, the average velocity dropped to $0.28 \mathrm{~m} / \mathrm{s}$. With the increase in the cutting gangue part, the average velocity decreases gradually, and when the proportion of cutting gangue part increased to $66.7 \%$, the average speed was almost close to that of cutting single gangue medium. The working resistance to be overcome by the roller cutting gangue is much larger than that of cutting coal seam. When the phenomenon 


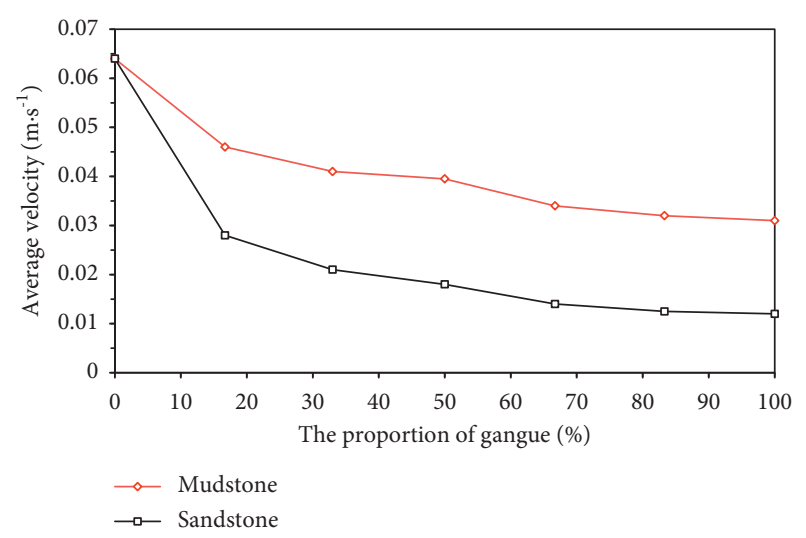

FIGURE 13: Relation of average speed and rock portion.

of top cutting occurs, even if there is only a small part of gangue, it will produce a large working resistance to the roller, leading to a sudden drop in the average speed.

\section{Conclusions}

The conclusions drawn from this study are summarized as follows:

(1) When taking the dynamic condition to keep the traction force and the rotation speed is unchanged, the roller always maintains a certain average speed of cutting forward. However, the instantaneous velocity fluctuates up and down in a small amplitude near the average velocity, presenting a "jump" phenomenon. The larger the medium strength is, the larger the jump amplitude is.

(2) If the roller traction force is small and the medium strength of coal and rock is large, the roller will produce negative instantaneous velocity, which can cut the medium repeatedly in the way of forward, backward, and forward again. That is to say, the phenomenon of "springback" occurs and springback is a reflection of the mechanical properties of coal and rock itself.

(3) When the phenomenon of "cutting top" of the coal cutter roller appears, the average cutting speed will decrease gradually with the increase of the gangue part, which presents a "nonlinear" relationship. The average velocity of cutting a small part of gangue will lead to a sudden drop, whereas cutting a large part of gangue will be close to that of cutting a single gangue medium.

(4) The average cutting speed and reverse torque are good indices to evaluate the cutting medium's type. If the relevant sensors can be used to capture the dynamic response characteristics of the field of drum cutting medium, the coal rock medium type ahead of the roller can be determined in real time according to the dynamic parameters. At the same time, if the lithology of the medium ahead of the working face is known, the dynamic response characteristics of the roller coal cutter can also be predicted in advance.

\section{Data Availability}

The data used to support the findings of this study are available from the corresponding author upon request.

\section{Conflicts of Interest}

The authors declare that they have no conflicts of interest.

\section{Acknowledgments}

This work was supported by "Key Research Development and Promotion Special Project of Henan Province (Grant no. 212102210229)" and "Key Research Projects of Higher Education Institutions of Henan Province (Grant no. 21A440014)."

\section{References}

[1] S. Liu, "Research on cutting performance of shearer drum and cutting system dynamics," Doctoral Thesis, China University of Mining and Technology, Xuzhou, China, 2009.

[2] J. Yang, "Research on the affect relationship between shearer working condition parameters and coal and rock hardness," Doctoral Thesis, China University of Mining and Technology, Beijing, China, 2013.

[3] Q. Zhang, G. Gu, and J. Liu, "Research on coal and rock type recognition based on mechanical vision," Shock and Vibration, vol. 2021, Article ID 6617717, 10 pages, 2021.

[4] Q. Zhang, Z. Liu, H. Wang, Y. Tian, and C. Huang, "Study on coal and rock identification based on vibration and temperature features of picks," Coal Science and Technology, vol. 46, no. 3, pp. 1-9, 2018.

[5] E. Zha, S. Wu, Z. Zhang et al., "Mining-induced mechanical response of coal and rock at different depths: a case study in the Pingdingshan mining area," Arabian Journal of Geosciences, vol. 13, no. 19, pp. 30-41, 2020.

[6] Y. Xing and B. Liu, "Characteristic equations and closed-form solutions for free vibrations of rectangular mindlin plates," Acta Mechanica Solida Sinica, vol. 22, no. 2, pp. 125-136, 2009.

[7] J. Yang, S. Fu, H. Jiang, X.-Y. Zhao, and M. Wu, "Recognition of cutting hardness of coal rock properties based on fuzzy criteria," Journal of China Coal Society, vol. 40, no. S2, pp. 540-545, 2015.

[8] J. Sun, "Chen Bang, an approach to coal and rock recognition via- statistical modeling in dual-tree complex wavelet domain," Journal of China Coal Society, vol. 41, no. 7, pp. 1847-1858, 2016.

[9] J. Liu, C. Ma, Q. Zeng, and G. Kuidong, "Discrete element simulation of conical pick's coal cutting process under different cutting parameters," Shock and Vibration, vol. 2018, Article ID 7975141, 12 pages, 2018.

[10] J.-Y. Park, H. Kang, J.-W. Lee et al., “A study on rock cutting efficiency and structural stability of a point attack pick cutter by lab-scale linear cutting machine testing and finite element analysis," International Journal of Rock Mechanics and Mining Sciences, vol. 103, pp. 215-229, 2018.

[11] X. Yang, Y. Xue, and J. Zhou, "Stress distribution and fluctuation cycle on the rack face of the rock cutting tool," Shock and Vibration, vol. 2019, Article ID 6830519, 13 pages, 2019.

[12] H. Lai, Mechanical Rock Fragmentation, Central South University of Technology Press, Changsha, China, 1991. 
[13] Y. Liang and S. Xiong, "Forecast of coal and rock interface based on neural network and dempster-shafter theory," Journal of China Coal Society, vol. 28, no. 1, pp. 86-90, 2003.

[14] F. Reng, "Study on the theory and method of coal and rockinterface recognition based on multi-sensor data fusion technique," Doctoral Thesis, Taiyuan University of Technology, Taiyuan, China, 2003.

[15] C. Liu, Q. Yang, and C. Li, "Simulation of shearer drum cutting with memory program controlling by fuzzy control," Journal of China Coal Society, vol. 33, no. 7, pp. 822-825, 2008.

[16] J. Sun and J. She, "Coal and rock image feature extraction and recognition based on support vector machine," Journal of China Coal Society, vol. 38, no. S2, pp. 508-512, 2013.

[17] J. Yang, H. Jiang, X. Ji, and M. Wu, "Vibration identification method of coal and rock hardness based on wavelet packet features," Coal Science and Technology, vol. 43, no. 12, pp. 114-117, 2015.

[18] S. Huang and J. Liu, "Research of coal and rock recognition technology based on GMM clustering analysis," Journal of China Coal Society, vol. 40, no. S2, pp. 576-582, 2015.

[19] W. Yang, J. Qiu, Y. Zhang et al., "Acoustic modeling of coal and rock interface identification," Coal Science and Technology, vol. 43, no. 3, pp. 100-103, 2015.

[20] G. Xue, X. Zhao, E. Liu Ermeng et al., “Time-domain characteristic extraction of coal and rock vibration signal in fullymechanized top coal caving face," Coal Science and Technology, vol. 43, no. 12, pp. 92-97, 2015.

[21] C. Li, L. Dong, Q. Wang, F.-Y. Wang, P. Hu, and X.-M. Xu, "Noise auto identification and de-noising method of coal and rock weak electromagnetic signals," Journal of China Coal Society, vol. 41, no. 8, pp. 1933-1940, 2016.

[22] L. Tian, J. Mao, and Q. Wang, "Coal and rock identification method based on the force of idler shaft in shearer's ranging arm," Journal of China Coal Society, vol. 41, no. 3, pp. 782787, 2016.

[23] X. Liu, D. Fan, Y. Tan et al., "New detecting method on the connecting fractured zone above the coal face and a case study," Rock Mechanics and Rock Engineering, vol. 54, no. 8, pp. 4379-4391, 2021.

[24] X. Xu and J. Yu Jing, Rock Fragmentation, China Coal Industry Press, Beijing, China, 1984.

[25] O. Su and N. Ali Akcin, "Numerical simulation of rock cutting using the discrete element method," International Journal of Rock Mechanics and Mining Sciences, vol. 48, no. 3, pp. 434-442, 2011.

[26] H. Jeong and S. Jeon, "Characteristic of size distribution of rock chip produced by rock cutting with a pick cutter," Geomechanics and Engineering, vol. 15, pp. 811-822, 2018.

[27] X. Liu, W. Jing, M. Zhou, and Y. Li, "Multi-Scale feature fusion for coal-rock recognition based on completed local binary pattern and convolution neural network," Entropy, vol. 21, no. 6, p. 622, 2019.

[28] F. Luo, L. Zhang, B. Du, and L. Zhang, "Dimensionality reduction with enhanced hybrid-graph discriminant learning for hyperspectral image classification," IEEE Transactions on Geoscience and Remote Sensing, vol. 58, no. 8, pp. 5336-5353, 2020.

[29] C. Yu, X. Wang, K. Pang, G. Zhao, and W. Sun, "Dynamic characteristics of a vibrating flip-flow screen and analysis for screening 3mm iron ore," Shock and Vibration, vol. 2020, Article ID 1031659, 12 pages, 2020.

[30] T. Lin, Z. Lian, Y. Meng, B. Yang, X. Wu, and Z. Xiao, "Finite elements method study on dynamic rock breaking in air drilling," Chinese Journal of Rock Mechanics and Engineering, vol. 27, no. S2, pp. 3592-3597, 2008.

[31] W. Liu, X. Qian, T. Li, Y. Zhou, and X. Zhu, "Investigation of the tool-rock interaction using Drucker-Prager failure criterion," Journal of Petroleum Science and Engineering, vol. 173, pp. 269-278, 2019.

[32] Z. Zhuang, ABAQUS Nonlinear Finite Element Analysis and Examples, Science Press, Beijing, China, 2005. 